\title{
JIT success in impact factor rankings
}

\author{
Journal of Information Technology (2007) 22, 1-2. doi:10.1057/palgrave.jit.2000074
}

S ince we re-launched the journal with a re-invigorated editorial policy in December 2003, we have made a point of not writing editorials unless there was a good reason. For this issue, the reason lies in the release of the latest Impact Factor Rankings, which have placed the Journal of Information Technology at 11th out of 71 journals in the field of Management. This puts us above journals such as Harvard Business Review, the Academy of Management Executive, the Journal of Management Studies, and the Journal of Management Information Systems, and just one place behind Management Science.

This success is the outcome of a number of factors including our re-invigorated editorial policy, energetic support from our publisher, Palgrave, in increasing awareness of the journal, and the excellent work of our regional editors, guest editors, reviewers, and authors. And, of course, it requires our readers to cite the journal in their own publications.

A key plank of the editorial policy has been to provide higher quality, more interesting, more timely, and more useful contents. This includes in addition to research papers, state of the art reviews, teaching cases, perspectives and debates, and special issues.
We have experienced increasingly high levels of submissions in the last 3 years and enjoyed a bumper crop in 2006. This has given us the feedstock for a review process designed to assist authors of high potential papers to convert them into publishable work. We have expanded our team of Regional Editors to manage this increase and have introduced an initial review by the Editors-in-Chief to provide immediate response to submissions that are inappropriate or unpublishable. We have also published several highly popular special issues on topical subjects. The current issue on Transfer and Diffusion of IT for Organizational Resilience is a case in point. We continue to welcome suggestions from our readers and offers to assist in guest editing a special issue.

A further reason for our success has been the support from our publisher since 2004, Palgrave. They have actively marketed the journal which has brought us more readers and authors. This combination has contributed to our increased impact.

One reason why we are always keen to publish work that builds on research that we have published is that it offers the opportunity to increase the citation rates for the journal. This benefits authors, new and old, as well as the Journal.

Table 1 Top 20 management journals by Impact 2005

\begin{tabular}{llrrrc}
\hline Rank & Abbreviated journal title (linked to journal information) & ISSN & Total cites & Articles & Impact factor \\
\hline 1 & Mis Quart & $0276-7783$ & 2395 & 28 & 4.978 \\
2 & Acad Manage Rev & $0363-7425$ & 6387 & 37 & 4.254 \\
3 & Admin Sci Quart & $0001-8392$ & 5906 & 13 & 2.719 \\
4 & Hum Resource Manage & $0090-4848$ & 1167 & 39 & 2.378 \\
5 & Acad Manage J & $0001-4273$ & 6944 & 60 & 2.200 \\
6 & Organ Sci & $1047-7039$ & 3142 & 44 & 1.989 \\
7 & Strategic Manage J & $0143-2095$ & 6137 & 66 & 1.897 \\
8 & Res Policy & $0048-7333$ & 2470 & 93 & 1.835 \\
9 & Leadership Quart & $1048-9843$ & 794 & 38 & 1.750 \\
10 & Manage Sci & $0025-1909$ & 8367 & 136 & 1.669 \\
11 & J Inf Technol & $0268-3962$ & 347 & 19 & 1.543 \\
12 & JManage & $0149-2063$ & 2562 & 44 & 1.535 \\
13 & Inform Manage-Amster & $0378-7206$ & 1230 & 62 & 1.524 \\
14 & Corp Gov & $0964-8410$ & 334 & 64 & 1.431 \\
15 & J Oper Manag & $0272-6963$ & 1071 & 38 & 1.419 \\
16 & J Manage Inform Syst & $0742-1222$ & 1167 & 31 & 1.406 \\
17 & Harvard Bus Rev & $0017-8012$ & 4475 & 114 & 1.404 \\
18 & JManage Stud & $0022-2380$ & 1622 & 66 & 1.326 \\
19 & Acad Manage Exec & $0896-3789$ & 930 & 41 & 1.319 \\
20 & Organization & $1350-5084$ & 507 & 35 & 1.280 \\
\hline
\end{tabular}

Source: Thomson Scientific (2006).

Note: The table gives total citations for each journal during 2005. The impact factor was calculated from the cites relating to $2003-2004$ articles which totaled 71 . 
It is important for all authors and readers that the Journal is recognized as a quality outlet for research. Conscious that many schools create lists of 'approved' journals for the purposes of measuring quality of output we display above a table showing the top 20 management journals by impact. Below we explain how the impact factors are calculated.

\section{Journal impact factors 2005}

Journal impact factors are calculated annually by the Thomson Scientific. Journals are classified by discipline. The Journal of Information Technology sees Management as its principal reference discipline although it also makes an impact in both Information Science and Computer Science.

The 2005 impact factors were calculated in 2006 as follows:

The impact factor is the average number of times articles from the journal published in the prior
2 years (i.e. 2003-2004) were cited in the current year (2005).

$$
\frac{(2003 \text { cites }+2004 \text { cites })}{(\text { Total articles published } 2003-2004)}
$$

The Journal of Information Technology's Impact Factor is 1.543. This positions it within the following disciplines:

\section{Management}

2005: $11 / 71$ (top $15 \%$ )

Information Science \& Library Science 2005: 8/55 (top 15\%)

Computer Science, Information Systems

2005: 22/83 (top 27\%)

The top 20 management journals are shown in Table 1.

Leslie Willcocks, Chris Sauer Spring 2007 